\title{
Drying and sortation to improve green beans and cup quality of Wamena coffee
}

\author{
Adnan*, and Martina Sri Lestari \\ Papua Assessment Institute for Agricultural Technology, J1. Yahim No. 49, Sentani, Jayapura, Papua, \\ Indonesia
}

\begin{abstract}
Drying and sortation are the most important steps to improve green coffee beans and cup quality. However, farmers very often neglect these steps. Therefore, a simple technique and soft approach are required to encourage farmers to implement drying and sortation technology. The study aim is to assess suitable drying and sortation technology to improve green coffee beans and cup quality to local culture in Jayawijaya Regency, Papua. The study was conducted using 2 factors; a. Combination of drying floor using a tarp and without sortation (DFWTS), b. Combination of drying tables and with sortation (DTWS). Drying tables were designed as two separate parts. The first part was the permanent tables, and the second part was removable boxes in dimension $80 \times 80 \mathrm{~cm}$ located on top of the permanent tables. Descriptive analysis was conducted based on SNI 012907-2008 by the Indonesian Coffee and Cocoa Research Institute. The results show DTWS produce green coffee beans in compliance with SNI 012907-2008 at 4a grade, compared to DFWTS is rejected. Green coffee beans quality is likely to affect cup quality. DTWS obtain cup quality score 83.0 compare to DFWTS is 81.25 . In conclusion, DTWS improve green coffee beans and cup quality.
\end{abstract}

\section{Introduction}

Papua is potential as a coffee production area in Indonesia. However, coffee production in Papua is still low, compared to other production areas, e.g., Aceh, North Sumatera, East Java, and South Sulawesi. Papua coffee production in 2015 is 2,018 ton, $0.3 \%$ of Indonesia's total production. The production area in Papua is 4,334 ha with the immature and damaged area are 4,253 ha and 1,383 ha, respectively [1].

Most of the coffee area in Papua is located in Jayawijaya Regency. Jayawijaya Regency produces around 87.9 ton green beans from an area of 2,400 ha. Coffee production from several districts on this regency is known as Wamena coffee (Table 1). Coffee plantation is located in highland are, above $1600 \mathrm{~m}$ asl. The plantation is cultivated organically, without chemical fertilizer and pesticides. Specific environment conditions in this area produce unique coffee aroma and flavor, compare to other origins [2].

\footnotetext{
* Corresponding author: aalbahry@yahoo.com
} 
Table 1. Green coffee beans area and production of Jayawijaya Regency in 2019

\begin{tabular}{|l|c|r|}
\hline District & Area (ha) & Production (ton) \\
\hline Welesi & 366.9 & 32.6 \\
\hline Siepkosi & 384.4 & 3.0 \\
\hline Asotipo & 243.3 & 1.5 \\
\hline Ubykosi & 106.0 & 1.7 \\
\hline Walagame & 147.7 & 1.3 \\
\hline Wolo & 157.6 & 3.8 \\
\hline Piramyd & 150.0 & 12.5 \\
\hline Asologaima & 157.0 & 4.3 \\
\hline Pelebaga & 191.0 & 2.8 \\
\hline Yalengga & 105.6 & 7.6 \\
\hline Usilimo & 203.4 & 3.6 \\
\hline Kurulu & 187.6 & 13.3 \\
\hline
\end{tabular}

Source: District office 2019 [2]

Coffee will become a valuable commodity for economic development in Papua. Previous researches suggest that coffee can improve farmers' welfare in Papua. In general, coffee farmers live in villages and gain low income. Improving the quantity and quality of green coffee beans will increase coffee prices. Thus, farmers will attain a higher incomes [3, 4].

Improving the quantity and quality of green coffee beans can be achieved by implement varieties selection, shade-tree management, optimum spacing and fertilization, pruning, pest and disease management, and good postharvest handling practice. Postharvest practice in coffee starts from harvest only red cherries; pulping; washing; wet, dry or semi processes; drying; milling; sortation, and storage. Each step is crucial and important to produce good quality of green coffee beans [5].

Drying is an important step to produce good quality of green coffee beans. Moisture content (MC) more than $12 \%$ dry weight $(\mathrm{dw})$ is a suitable environment for fungus growth in green coffee beans. The fungus will leave a residue in the form of ochratoxins, a potential carcinogen [6]. Sortation also plays important roles to separate good and damaged beans. Appropriate sortation will increase the grade quality of green coffee beans, which will lead to a higher price in the market [7].

Several traders complain regarding the quality of the green beans of Wamena coffee. The quality of green beans still does not meet the market standard. Moisture content higher than $12 \% \mathrm{dw}$ and mouldy beans present, and as consequences reduce green beans quality and price. From our observation, these problems occur because of a lack of proper green beans dryer and sortation. Traditionally, farmers dry green beans using a patio or tarp. An alternative method to drying green beans using patio or tarp is using drying tables. It has been suggested that drying tables produce a better quality of green coffee beans [8].

However, drying tables are a new approach for local people in Wamena. Local people need to be convinced that this different drying technique compares to their habit, can improved green coffee beans quality. Thus, the study aim is to assess suitable drying and sortation technology to improve green coffee beans and cup quality to local culture in Jayawijaya Regency, Papua.

\section{Materials and methods}

\subsection{Materials and site}

Green coffee beans species Coffea arabica var Linie S 795 were collected from processing plant of farmer group Alua Marian at Waga-waga village, Kurulu District, Wamena, 
Jayawijaya Regency during harvest season on Mei-October 2019 (longitude -3.959110, 138.925786; altitude 1660 m AMSL).

\subsection{Methods}

The red cherries were harvested by selective hand picking. The farmer picks only the ripe coffee cherries by hand, while the unripe cherries are left of the tree. The unripe cherries are reappraised a few weeks later. This process is repeated until all the ripe cherries have been picked during the harvest season. Cherry-picking is a labor-intensive method, with pickers setting out and filling baskets. Then these baskets are emptied into larger collection bags.

Farmer process the green beans using dry method. Firstly, a manual machine separates the pulp and the skin from the green beans on the pulping process. Secondly, the green beans were washed using water to remove the mucilage around the seed. Furthermore, the green beans were fermented for $12 \mathrm{~h}$ on storage. Afterward, the green beans were sun-dried using two different methods.

The study was conducted using 2 factors; a. Combination of drying floor using a tarp and without sortation (DFWTS). b. Combination of drying tables and with sortation (DTWS) (Figure 1a, b). Drying tables were designed as two separate parts. The first part was the permanent tables, and the second part was removable boxes in dimension $80 \mathrm{x} 80 \mathrm{~cm}$ located on top of the permanent tables.

Descriptive analysis was conducted based on SNI 01-2907-2008 by the Indonesian Coffee and Cocoa Research Institute. The parameters were life insects, routed/mouldy, moisture content, foreign matter, size, and defect number. Cup testing characteristics were fragrance, flavor, aftertaste, acidity, body, uniformity, balance, clean cup, sweetness, overall, taint/defect, and comments.
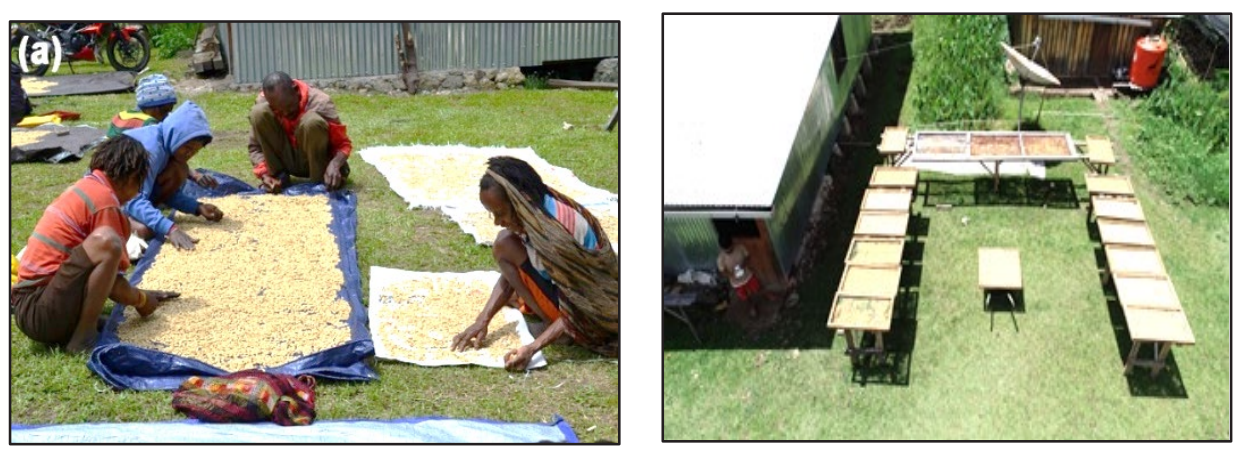

Fig. 1 (a) Combination of drying floor using a tarp and without sortation (DFWTS), (b) Combination of drying tables and with sortation (DTWS)

\section{Results and discussion}

Table 2 shows green beans quality on DFWTS and DTWS. Routed/mouldy beans are present in DFTWS, while SNI 01-2907-2008 requires zero present. The presence of routed/mouldy beans may be caused by high moisture content. Moisture content in green coffee beans should not more than $12.5 \%$. Recent evidence suggests moisture content and water activity correlate to fungal infection. Higher moisture content and water activity lead to ochratoxin production. Moisture content and water activity in jute bags should be below $12 \%$ and 0.75 , respectively [9]. 
Table 2. Green coffee beans quality

\begin{tabular}{|l|c|c|}
\hline \multicolumn{1}{|c|}{ Characteristics } & DFWTS & DTWS \\
\hline life insects & Absent & Absent \\
\hline routed/mouldy & Present (N.C.) & Absent \\
\hline moisture content & $12.9 \%$ (N.C.) & $10.9 \%$ \\
\hline foreign matter & $0 \%$ & $0 \%$ \\
\hline Size & $\begin{array}{c}\text { Medium (passed Sieve No 16, } \\
\text { retained Sive no 15) }\end{array}$ & $\begin{array}{c}\text { Medium (passed Sieve No 16, } \\
\text { retained Sive no 15) }\end{array}$ \\
\hline defect number & 47.8 & 54.75 \\
\hline Conclusion & $\begin{array}{c}\text { Not conform to SNI 2907-2008 } \\
\text { because routed/ mouldy beans are } \\
\text { present, moisture content more } \\
\text { than 12.5\% }\end{array}$ & $\begin{array}{c}\text { Conform to SNI 2907-2008 grade } \\
4 \mathrm{a}\end{array}$ \\
\hline
\end{tabular}

DFWTS = Combination of drying floor using a tarp and without sortation; DTWS = Combination of drying tables and with sortation; N.C. = not conform to SNI 01-2907-2008

DTWS produce a better quality of green coffee beans, compare to DFWTS (Table 2). Moisture content in DTWS is $10.9 \%$, which is below the maximum requirement at $12.5 \%$. It has previously been observed that solar dryers using a box or table are suitable for drying coffee beans. Drying rate depends on solar radiation intensity and wind velocity [10].

Previous research has reported drying methods affect the quality of green coffee beans. Intermittent sun-drying produces a better quality of green coffee beans compare to constant convective drying. In North Sumatera, farmers use different drying methods based on coffee species. Arabica was fermented and was sun-dried up to $80 \% \mathrm{MC}$, then were dried in a greenhouse until 12\% MC. Furthermore, Robusta was sun-dried without any treatment [11].

Pulping reduces drying time. Pulped beans require $145 \mathrm{~h}$ drying time to reach $<12 \% \mathrm{MC}$, compared to the natural beans are $251 \mathrm{~h}$ drying time on the drying floor. Mechanical dryer decreases drying time to $28-37 \mathrm{~h}$ for pulped beans and 91-139 $\mathrm{h}$ for natural beans. The ambient air temperature, the exposure time, the initial and final moisture content of the product affect the drying dynamics and have a significant effect on the coffee quality. The removal of the pulp and the skin of the beans contribute to the drying time [12].

Routed/mouldy beans were present on DFWTS, while absent on DTWS (Table 2). Mouldy beans are described as the aroma of wet wood, wet mushroom and mould. Longer drying time on sun drying method is potential to produce more mouldy character [13]. Rainfall and high temperatures during the harvest season will promote conditions that increase the risk of mouldy [14].

The drying and sortation method did not affect foreign matter and bean size (Table 2). The absence of foreign matter suggests that farmer has implemented a good handling processing to avoid debris, dust or rock. Bean size is related to radiation levels and rates of nitrogen supply. Increasing nitrogen levels and reducing radiation simultaneously are likely to increase the bean size [15]. Other elements such as the concentration of magnesium relative to calcium $(\mathrm{Mg}: \mathrm{Ca})$ and the concentration of nitrogen relative to phosphorus $(\mathrm{N}$ : P) are also essential for bean size [16].

In general, drying green coffee beans involves two types: (1) sun-drying, (2) mechanical dryers. The choice of the drying method employed depends on economic factors and the type of processing. Dry processing needs more time to reach the required MC, thus mechanical dryers are not recommended because it will demand a high cost. However, mechanical dryers will decrease drying time and risk of microbial contamination for wet-processed coffees. Microbially derived metabolites can diffuse into seeds and remain after the roasting process and affect the quality of the final coffee beverage [17]. 
Drying green coffee beans direct on the floors are potentially contaminated by animals such as dog and pig. Local people pet dog and pig, and these animals often pass-through green coffee beans pile on a tarp. This condition does not meet the standard requirements. Drying green coffee beans on drying table will prevent animal and other contamination such as dirt and soil.

In the previous study, the high physical contamination is caused by traditional drying techniques. Coffee beans are contaminated with rocks, gravels, dirt, and branches, resulting from the beans are placed on the floor or soil [18]. Higher risk to other contaminants such as ochratoxin A occurs in a longer period of drying time [19].

Coffee grade on DTWS value can still be improved by better sorting implementation. The defect number of DTWS is relatively high, around 54.7 (Table 2). This defect number can still be reduced to improve the quality of the coffee beans. Sortation training for local people is required. Price incentives at higher green coffee beans grade will stimulate local people to learn and implement sortation. However, DTWS conform to SNI 2907-2008 grade 4a. This grade implies DTWS produce green coffee beans quality are acceptable to the market standard. In contrast, DFWTS do not conform to SNI 2907-2008 and will be rejected by the market. The farmer will gain low income to produce green coffee beans using DFWTS method.

Cup testing result both methods are in the specialty grade score (Table 3 ). The minimum score for obtaining a specialty grade is 80 . The score of DTWS is 83 , higher compare to DFWTS of 81.25. This value is correlated to green coffee beans quality in Table 2 . Roted/mouldy beans presence in DFWTS. These defective beans affect the coffee taste. Rated/moldy beans result in cereal, papery, and astringent aftertaste in a coffee drink. These defects are undesirable because it produces unpleasant taste to the coffee drinker. Natural and sun-dry processing produce more coffee defects, compared to other drying methods. Prolong sun drying for 7 up to 21 days, where the temperature could not be carefully controlled caused more defect beans. Immature beans, black, sour, black immature, bored, or insect-damaged and broken beans are the most affected to cup quality [20].

Sorting plays important role to increase coffee quality. A previous study indicated sorting of damaged beans could significantly minimize potato taste defect in coffee beans [21]. Green coffee beans were characterized by a peasy odor note cause an undesirable peasy off-flavor. This off-flavor is referred to as potato taste defect, also other sensory attributes such as roasty and earthy in cup testing. The problem occurs due to improper sorting. Higher coffee value on the market is from selected good quality cherries [22].

In general, local people accepted DTWS because this method increases the quality of green coffee beans, which leads to a better price. Removing part of DTWS is practice for their habit. Each member of the farmer group can dry their green coffee beans, separate from other members. Thus, their income can be calculated on how much green coffee beans in the box as removing part of DTWS. 
Tabel 3. Cup testing score

\begin{tabular}{|l|c|c|}
\hline \multicolumn{1}{|c|}{ Characteristics } & DFWTS & DTWS \\
\hline Fragrance/ aroma & 7.75 & 7.75 \\
\hline Flavor & 7.50 & 7.50 \\
\hline Aftertaste & 7.50 & 7.50 \\
\hline Acidity & 7.00 & 7.50 \\
\hline Body & 7.50 & 7.75 \\
\hline Uniformity & 10.00 & 10.00 \\
\hline Balance & 7.00 & 7.50 \\
\hline Clean Cup & 10.00 & 10.00 \\
\hline Sweetness & 10.00 & 10.00 \\
\hline Overall & 7.00 & 7.50 \\
\hline Taint/defect & 0.00 & 0.00 \\
\hline Final Score & 81.25 & 83.00 \\
\hline Score notation & Specialty Grade & Specialty Grade \\
\hline \multirow{2}{*}{ Comments } & $\begin{array}{l}\text { Caramelly, Spicy, Basmatic Rice, } \\
\text { Baggy, Papery, Cereally, Astringent } \\
\text { Aftertaste }\end{array}$ & Caramelly, Nutty, Spicy \\
\hline
\end{tabular}

DFWTS = Combination of drying floor using a tarp and without sortation; DTWS = Combination of drying tables and with sortation.

\section{Conclusions}

The present study was designed to assess suitable drying and sortation technology to improve green coffee beans and cup quality to local culture in Jaya Wijaya Regency, Papua. In this study, DTWS were found to produce green coffee beans in compliance with SNI 01-29072008 at 4 a grade, compared to DFWTS is rejected. Green coffee beans' grade is likely to affect cup quality. DTWS obtain a cup quality score of 83.0 compared to DFWTS is 81.25. In conclusion, DTWS improve the green coffee beans and cup quality of Wamena coffee.

Acknowledgement. Thank you to Indonesian Agency for Agricultural Research and Development, the Ministry Agriculture Republic of Indonesia for funding; Syahrul, SP, agriculture extension officer for running field experiment in Wamena

\section{References}

1. Ditjenbun: Statistik Perkebunan Indonesia: Kopi 2015-2017. Direktorat Jenderal Perkebunan, Kementerian Pertanian (2017).

2. T.Wandik, N.Waney, Y. Rori. J. Agribisnis dan Pengemb. Pedesaan. 2 (2020)

3. M.A. Purwadi. J. Manaj. Dan Bisnis. 2 (2018)

4. S.S. Sairdama, J. Agribisnis Kepul. 2(2013).

5. T. Kidist, G. Zerihun, E. Biniam. African J. Agric. Res. 14, (2019).

6. F. Wijayanti, S. Hariani. Pengaruh Pengeringan Biji Kopi dengan Metode Rumah Kaca dan Penyinaran Sinar Matahari Terhadap Kadar Air Biji Kopi Robusta (Coffea Robusta). In: Prosiding Seminar Nasional Sains Dan Teknologi (2019)

7. D.Z. Azis, M. Rivai. J. Tek. ITS. 7, (2018)

8. T.S. Pamungkas, G. Wicaksono, R. Yunita. J. Inov. Sos. Pengabdi. Masy. 2, (2019)

9. L.M. Broissin-Vargas, R. Snell-Castro, J.J. Godon, O. González-Ríos, M.L. SuárezQuiroz. J. Appl. Microbiol. 124, (2018)

10. A. Qadry, T. Hutagalung, K.J. Harry, R.A. Napitupulu, H. Ambarita . Experiemental study on solar dryer with extended flat plate collector. In: IOP Conference Series: Materials Science and Engineering (2020) 
11. P. Siagian, E.Y. Setyawan, T. Gultom, F.H. Napitupulu, H. Ambarita. A field survey on coffee beans drying methods of Indonesian small holder farmers. In: IOP Conference Series: Materials Science and Engineering (2017)

12. P.D.D. Oliveira, M.A.M. Biaggioni, F.M. Borém, E.P. Isquierdo, M.D.O. Damasceno. Sci. Lavras. 13, (2018).

13. W.B. Sunarharum, S.S. Yuwono, N.B.S.W. Pangestu, H. Nadhiroh. Physical and sensory quality of Java Arabica green coffee beans. In: IOP Conference Series: Earth and Environmental Science (2018).

14. J. Kath, V.M. Byrareddy, S. Mushtaq, A. Craparo, M. Porcel. Clim. Risk Manag. 32, (2021)

15. A.D. Bote, J. Vos. J. Life Sci. 83, (2017)

16. A. Yadessa, J. Burkhardt, E. Bekele, K. Hundera, H. Goldbach. African J. Agric. Res. 14, (2019).

17. G.V. de M. Pereira, D.P. de C. Neto, A.I.M. Júnior, Z.S. Vásquez, A.B.P.Medeiros, L.P.S. Vandenberghe, C.R. Soccol. Food Chem. 272, (2019)

18. R. Fadhil, Q. Qanytah, D.Y. Hastati, M.S. Maarif. Polytech. Soc. Manag. Sci. 26, (2018)

19. J.M. Barcelo, R.C. Barcelo. Risk Assess. 35, (2018)

20. W.B. Sunarharum, S.S. Yuwono,H. Nadhiroh. Adv. Food Sci. Sustain. Agric. Agroindustrial Eng. 1, (2018)

21. J. Bigirimana, A. Gerard, D. Mota-Sanchez, L.J. Gut. Florida Entomol. 101, (2018)

22. K.J. Flambeau, W.J. Lee, J. Yoon. Food Sci. Biotechnol. 26, (2017)

23. S. Mangiwa, Y.R. Yabansabra. SAINS J. MIPA dan Pengajarannya. 16, (2016)

24. S. Mangiwa, A. Futwembun, P.M. Awak. Hydrog. J. Kependidikan Kim. 3, (2015) 